\title{
Using Contemporary Media as Supplementary Tool to Improve Pharmacology Education on College Synthetically
}

\author{
Ying Song $^{1^{*}}$, Yan Xiao ${ }^{1}$, Bi-Wei Song ${ }^{1}$, Hai Feng ${ }^{1}$ \\ Department of Pharmacology, Zhejiang University of Technology, Hang Zhou, Zhejiang, China
}

\begin{abstract}
Currently, the pharmacology teaching is popularized and becomes one of indicators and important compositions of all curricula initial in medical or nurse's college. But it is very difficult for student, particularly English is not his native language. This article design will take students as the primary object, set up a perfect test database, and conduct opening studying mode in form of "QQ group" or "pharmacology blog" discussion. To solve it that the teaching contents of pharmacology are very abstract and logistical, and they are difficult for students to master most contents in a short period. All of these will play an active role in pharmacology studying and teaching.
\end{abstract}

Keywords-Reforming of pharmacology; test database; experiment; Pharmacology audio; QQ group

\section{Introduction}

Pharmacology is a science on the interaction between drug and organisms (including animal, human body and pathogen) and their mechanism. It is also mainly to explain the pharmacokinetics and pharmacodynamics, to provide scientific basis for correct and reasonable clinical use of drug, and to develop new drugs to provide safe and effective pharmacological evidences. Furthermore, the pharmacology is an main curricula, and it mutually penetrates with other subjects and plays the important role of base subject and fields for our pharmacy and other nurse's college. Because of short duration of basis medical time for other nurse or pharmacy student, it is difficult for them to master specialty words in short time. Although medication management is a complex multi-stage and multi-disciplinary process, involving doctors, pharmacists, nurses and patients, it is recognized that nurses are the final stage of defense and check for ${ }^{[1,2]}$. It is important for nurse and pharmaceutist to master the pharmacology knowledge.

However, the teaching contents of pharmacology are very abstract and logistical, and involves with serious

\footnotetext{
${ }^{1 *}$ To whom correspondence should be addressed. Tel.: 0086-0571-88320535; Fax: 0086-0571-88320535; E-mail: songying@zjut.edu.cn.

This work was supported by the fund from the Reform science of Zhejiang University of Technology (No. JG0949).
}

contradiction problem between teaching and studying. During the studying process, the students usually confused with excessive professional words and high information volume, which increases their burden on digestion and absorption after class. In a word, it is very difficult for students, particularly English is not his native language.

The current urgent problem in pharmacology teaching is how to let students master much knowledge, turn the passive study to active, and improve their study interest in the limited period.

In China, college teacher actively conduct practice and exploration in teaching and get achievements. However, how to make the students effectively and fast master the basic pharmacological knowledge is yet one of the issues existing in current teaching. Recently, many disciplines adopt many methods to separate teaching from examination, and promote improvement of quality of teaching and learning, such as increasing pictures in discipline teaching, editing necessary vocabulary handbook, and establishing the test bank. Our practice proves that establishment of test bank is rather applicable to the pharmacology teaching and it is a study method valuable to be popularized.

During the entire pharmacology teaching process, we try to on basis of the students as main object, try to use "QQ group” as the discussion platform, carry out questions-based discussion type open study, synchronously set up pharmacology experiments, primarily try to establish a reform mode of comprehensive entire-process examination, and finally realize pharmacology teaching reforming.

\section{Rationally arranging teaching materials and selecting important chapters to conduct students}

Correct selection of teaching materials is the first step of successful teaching. Firstly, according to teaching outline, we prepared to provide student lecture and key points depending on the class contents before class. Its merits are that the class key points is consistent with our teaching system, are easily acceptable by students, and teacher could make use of the whole teaching resource. 
The classical pharmacology teaching involve following contents and we basically divide them into following three parts: (1) Generals: drug pharmacokinetics (including absorption, distribution, metabolism and excretion of drug), drug pharmacodynamics (including action mechanism of drug, action of drug to human body and interaction between drugs), and factors affecting drug action; nursing students' pharmacological knowledge and calculation skills ${ }^{[3]}$. (2) mechanism of drug action- (including Acetylcholine receptor agonists, cholinoceptor blocking drugs, anticholinesterase, adrenergic receptor blocker and adrenoceptor agonists). (3) Details description (the drugs for central and peripheral nervous system, cardiovascular system, adrenal cortex hormone, antipyretics, and drug for chemical therapy). The teacher shall rationally arrange class-hour rhythm and well enjoy classes.

In summary, the pharmacology teaching materials involve many contents and it is a high burden for students to master during one term. We select several important chapters as the main lecture contents, and consider others as selfstudies datum by students themselves, and appoint some exercises for intensifying.

We select lecture contents on basis of important pharmacology theoretical, which base on sequence of detail description after general, and list the chapters which would used in future job as key points: antihypertensives, antibiotics and glucocorticoid. And then we conduct conceptual diagram type lecture (first raised by professor Joseph D. Novak of Education Department of Cornell University in 1972) and pay more attention on these chapters. The conceptual diagram, as an effective teaching tool, since being raised has been widely used in western countries and become a common teaching mode. With conceptual diagram, students could learn actively, analyze and sort out the key pharmacology words, instead of passive memory of them, and systemize the knowledge, which is very advantageous to develop their intelligent space.

\section{Establishment of pharmacology teaching test bank and analysis of its merits and demerits}

The pharmacology is the base course of clinical medicine and the bridge course between the pharmacy and medicine. Well learning of the pharmacology closely relates to soundness of students' professional knowledge system and measures their competitive e power in future job, and thus the pharmacology course is an important professional course for students of pharmacy specialty. Currently, the pharmacology education faces an urgent issue how to join the international practice. Under the guidance of teaching policy popularized by the Education Ministry, we greatly popularize the pharmacology teaching in an effect to make students surely master the professional knowledge, timely understand the latest pharmacological knowledge, review latest international lectures, ceaselessly improve their ability, and put a sound foundation for their future competition. In a sense, introduction of the pharmacology teaching is a new trail for our pharmacology and other nurse education for joining the international pharmacy field.

Currently, the modern multi-media teaching is basically realized, however some weaknesses gradually occur in its wide application, such as, the pace of teaching is excessively high, students in class remember some concepts, but they are difficult in review after class, and homework is not perfect. There is a big gap between domestic teaching and students learn in pharmacology, and especially in development of new drugs. In the entire class the teacher is busy in translation and explain the profession vocabularies and neglects passing on the pharmacology knowledge. With this mode, the students merely master the English special vocabularies and poorly master the pharmacology knowledge. Hence, it is necessary to reform the multi-media teaching scheme. For example, a progressive approach is used. A special word occurring at first is attached with its English notation, which at re-occurrence will be entirely substituted by the English. This will make the students recall and gradually remember the said special word. At immediately before end of the chapter, the lecture is given entirely, and then the students are tested. Secondly, it is absolutely necessary to establish a pharmacology teaching test bank to aid the teaching and help students recall the class contents after the class, and perfect their knowledge system, which may overall examine students' mastering degree of the learn knowledge, facilitate examination-teaching-separation, and ceaselessly improve the teaching quality. The examinations were usually assigned by the classroom teacher on basis of his actual progress. Though the classical teaching is flexible too, some demerits occur due to the subjective assignment: The subjective assignment is relatively difficult to check the teaching quality, to ascertain a standard, and to overall test the students' mastering degree of the learn knowledge. Thus, establishment of pharmacology teaching test bank is one of important means for pharmacology teaching.

The assignment is made in accordance with teaching program by teachers who manager this whole course for many years and are experienced in teaching to make the test bank creditable. At the first, the test questions shall be rigor and diversified, and the assignments flexible and objective. Moreover, the test questions are randomly taken from the said bank for objective, overall and fair check the teaching and learning quality. On basis of the difficulty grade and types of test questions specified by the examination program, the examination shall include both the difficult questions and the simple basic ones, but they shall be kept at a proper difficult degree. Secondly, the test bank shall as far as possible include most key points of the course, the said key points shall be evenly and rationally distributed, and shall embody the key points in chapters and sections as the program for proper selection and for usual prospective testing of the students. the test questions shall have wide coverage, highlight the key points, and involve with aspects in the examination program. The test questions to be selected from the test bank shall be strictly controlled, and the questions of not high quality or of unclear conclusion or deviating from the program shall not be 
selected. In the end, the established test bank shall be ceaselessly upgraded, modified, deleted, expanded and perfected as per the teaching contents.

With constant deepening of teaching reform, the examination-teaching-separation realized through united assignment from the test bank is one of effective means to check the teaching quality and improve the teaching level. Establishing the pharmacology teaching test bank has the following merits: (1) it benefits to improve checking the comprehensiveness and objectivity of the teaching quality and learning quality ; (2) it benefits to find out the insufficiency in the last teaching and thus timely correct and improve the teaching level; (3) it benefits to release teachers' burden in assignment and marking; (4) it will decrease the impact by the man-made factors of assignment on the test questions results, and make the quality of examination paper obviously better than the one of teachers' subjective assignment; (5) testing with the questions randomly selected from the test bank will minimize or avoid errors in links from assignment-going over-marking, obtain students' actual achievement, and judge theirs mastering degree. Analysis of the data obtained from the examination makes the teaching laterally and longitudinally comparable; (6) it will make students prospectively learn and review the course after class and well master the said course; and (7) it will promote teacher-student channeling after class.

Obvious demerits also exist in the mode: It will make students excessively rely on the test bank, make them inattentive in or even absent from class, and merely get preparation just before examination, since the examination paper is randomly taken from the established test bank. Though some students do not well master the knowledge, they can get rather fair results as long as they answer a given amount of test questions. The above-mentioned demerits may be compensated and avoided through increasing the quantities of test bank and random taking examination paper.

\section{The problems encountered in establishing the pharmacology teaching test bank and the solution}

Establishment of the pharmacology teaching test bank requires massive manpower and material resources, but after completion it will generate many conveniences: (1) One may on basis of the existing pharmacology teaching test bank fast sort out the materials and data, make out the top quality and large-scaled problem sets to facilitate students' prospective exercise and review. (2) The test questions of a portion of chapter may be freely taken at any time for in-stage testing students to make them understand their learning state, and train their examination skill and the examination mental state ${ }^{\text {[3] }}$. (3) It will facilitate timely correction and adjustment of test questions and thus save time. (4) The examination-teachingseparation denotes that the examination paper is worked out by the personnel appointed by teaching administration sections instead of the class teacher himself. The examinationteaching-separation not only decreases the negative impact to the class teachers by the test, but also intensifies the degree of secrecy of the examination paper and the comprehensiveness of the tested contents, and improves the objectiveness and fairness of the test.

Currently, the establishment of pharmacology teaching test bank is yet under planning and it will encounter many problems: (1) it will face to shortage in fund and manpower and thus it is impossible to establish in one run, and the test bank reaches a given, complete and overall scale only through long-term collection; (2) science is ceaselessly refreshed and developed, even the test bank reaching a given scale shall be continuously upgraded, and the test questions shall be checked for rationality and shall be deleted and supplemented at any time. The test may be conducted in form of common examination or check in an effect to find out the nonreasonability and release teachers' burden to a given extent. However, the test bank shall be regularly overall checked; (3) the test bank shall be managed by several professional personnel to avoid disordered test bank and repeated test questions.

However, there is another importing and hard thing: how to spread all massages in the test bank to student.

\section{Reconstruction of test database and lecture contents and supplementation with contemporary media}

During organizing the collection of questions we systematically sort out the knowledge points specified in program and integrally consider the to-be-mastered knowledge points in sections, chapters and knowledge points. The examination questions shall cover every chapter and have diversified types and proper volume and difficult degree to keep good creditably. Hence, the questions in the collection of question shall cover most key knowledge points of the course as far as possible, and they shall be rationally and evenly distributed and stressed on some aspects. Usually, we could conduct prospective test to check students' degree. The questions are randomly taken from the said collection to ensure objective, overall and fair examination of the quality of teaching and learning ${ }^{[4]}$.

In addition, during the teaching process, we rationally and flexibly use the questions in test database to promote effect of teaching. Keeping the teaching progress orderly and rhythmic is very important. At first, students do not much adapt the teaching environment and we properly slow down the class progression, explain the concept of pharmacodynamics and pharmacokinetic clearly, e.g. the generals on drugs acting on peripheral nervous, since mastering of this chapter is directly related with the studying on following Cholinergic drugs, anticholinergic drugs, adrenal drugs and antiadrenergic drugs, and all of these will affect the studying on antihypertensives and anti-anginal drug. Hence, the generals are very important and they play key role as connecting link between the preceding and the following and they shall be in details explained in class, which gets good effects. Since the words involved in a chapter would occur for 
several times in the following chapters, students are advised to surely master them and impact on the following teaching progress. On the other hand, many medical words have prefix and use of corresponding word formation will facilitate students' memory, word "antibiotics" consists of “anti(meaning: resistant), bio-(meaning: life) and -tics (meaning: substance), we will summarize in class and enhance students' memory. If above chapters are well comprehended, the following chapters on antihypertensives, anti chronic cardiac insufficiency, anti-epileptic and anti-convulsant drugs will be relatively easily understood. However, the concepts on some chapters are confused, hence the teacher explains the drug action mechanism and meanwhile takes some examination question, which makes students fast master the key points of the class.

Usually, English is not the mother language to both students and teacher, and it is difficult for them in expression, listening and speaking. Hence at preparing lesson, the teacher shall mark the key words and at lecture repeat them, and after completion of a knowledge point he will put the question to students, make them carry question and doubt in the studying, discuss the focal and difficult points, fully play their studying activeness, and ceaselessly improve their foreign language level and professional knowledge ${ }^{[5]}$.

For well mastering the subject, the student should be required to prepare before class, find out the weak link failing to well master. In the class, students completely master the subject through asking teacher, and advance review each chapter based on schedule after class. In addition, the collection of questions doubtlessly builds a bridge between teachers and students, facilitates their exchange, and analyze some difficult and doubtful points. Especially, the teachers in class usually adopt multi-medium teaching mode, i.e. CAI (Computer Aided) teaching mode ${ }^{[3]}$ and (problem based learning (PBL) ${ }^{[6]}$ mode and in class the combine the traditional teaching with modern one, which usually gets better effects.

The group of QQ, just as the blog, which means web log and then is abbreviated as blog, a new style of writing is initiated in $21^{\text {st }}$ century (full name weblog). Blog was at first raised by Jorn Barger in December 1997, the first of blog occurred in 1998, its quantity greatly grew at end of 1999, in 2001 was massively expanded, and today becomes a individualized and colorful comprehensive platform where one may easily publish his experiences and effectively and freely exchange with others.

Combination of pharmacology teaching with the new element of $21^{\text {st }}$ century doubtlessly provides a new mode for pharmacology teaching reform. Due to limited class hours, it is necessary to establish the platform pharmacology QQ groups, where teacher could selectively put some questions for discussion or answer the questions, and make use of the strong function of review and message in the class. We could regularly put some lecture, note, question and latest research progress associated with the pharmacology contents of the course on the QQ groups, even about the breakthrough on pharmacology. It is very interesting that after end of the course we may sort out the articles into a record, including the following discussions and messages, which doubtlessly becomes a novel pharmacology studying material, and is better for the students unprecedentedly just as a references. For refresh of QQ groups massages, the teacher may divide the students in the class into groups and guide the students of each group make alternative refresh, which intensifies and supplements the pharmacology studying and improves their activeness on studying.

\section{Setting proper experiment courses and opening students' design scheme}

Pharmacology is a highly theoretical and practical base medical professional course, and for different teaching objectives and contents, the teacher usually work out proper experiment scheme with the teaching program. The experiments may be divided into two types. The classical verifying experiments could reach good effects and facilitate to strengthen students' base theoretical knowledge, and they should occupy most time for pharmacology experiment ${ }^{[7,8]}$, e.g. the experiments on impact on drug action by different dosages, different preparations and different application routes. After completion of lecturing on generals of pharmacology, the teacher may properly arrange this experiment to intensify students' perceptual knowledge and put a sound foundation for following experiments.

After mastering of base experiments, we try to open comprehensive experiment and design-orientated experiments to trigger students' research enthusiasm and improve their research quality and innovation capacity. This teaching mode may widen students' view field, and trigger their activeness and performance ability. Before completion of a class, the teacher shall brief the contents of the next class, or in the class during lecturing timely raise problems to introduce students' active thinking and discussion, and then conduct the experiment. After appointing experiment, one may adopt the mode of group-discussion, class-discussion or via QQ groups and final teacher's illustration and summarized in the class. Then the different groups made experiment according to their design and draw the results, which were discussed openly in groups for few days. At the last class discussion, the teacher may join the said discussion, timely answer students-raised problems, announce the discussion result and make detailed explanation to fast improve their thinking and performance ability.

\section{The feedback information of learning}

After we teach pharmacology by “QQ group”, to “talk with” every student, to do discuss under group, et al. Finally, our teacher makes a questionnaire survey to know how and what students think about. Our flow-process is as follows (Fig. 1). 


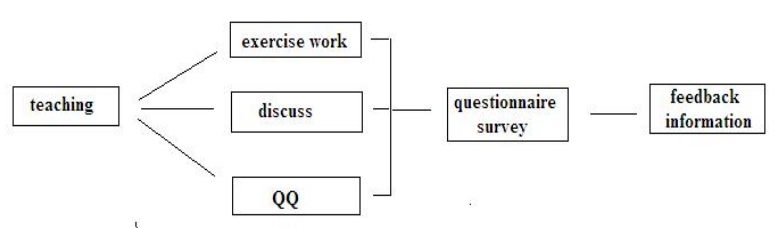

Fig.1 the flow-process of teaching and feedback information

In this questionnaire survey, we asked students 10 questions and offered some suggestion or advice, after finishing their lesson. All of these questions include:

1). How many times do you ask or make a discuss through the QQ group?

2). Do you consider that the $\mathrm{QQ}$ groups is the most convenient platform to make a discuss with teacher or student?

3). Could you give us some good advice for future pharmacology, and how to improve the QQ group and make it more convenient.

Finally, we have analysed the all of answers and draw a conclusion.

Almost all students think that it is the best platform, and usually visit the QQ groups. They suggested that all of homework and discuss could be finished through QQ groups, and it let easy to exchange massage between teacher and student, particularly be suitable for education in university.

\section{Summary and Prospect}

The assessment of effect of pharmacology teaching is difficult during the teaching process, and if the effects are found immediately prior to or after examination, it is somewhat late. During the teaching, we set collection of questions, transfer the question to student at class or through QQ groups, turn the "teacher-centered" teaching mode to "students-centered" and turn "class filling" to "student active acquired knowledge”, make students actively master knowledge, and improve their study attitude, self-studying capacity, solving capacity and channeling and expressing capacity.

Teachers set collection of questions, and conduct teaching on basis of the examination questions in form of class question- asking, which is a content of teaching activity, is embodied in the entire teaching process and also the destination of teaching. The "problem-based learning" focuses on understanding and solving problem, eliminates the demerits of simple traditional teaching mode. Establishment of pharmacology QQ discussing group fully fire students in activeness and participation, improve their knowledge and skill during the process of finding out answers and raising new problems, enhance their capacity in self-studying, analyzing and solving problems. We then sort out and publish QQ group message or PPT, and related reviews, which provides a novel and effective materials for pharmacology teaching.

In a word, the pharmacology teaching shall be reformed synthetically, and it conducts conceptual diagram type lecture in combination with test database, turns "class filling" to "student active acquired knowledge", and opens innovative experiment to enhance students' ability of performance and elaborative. Establishment of pharmacology blog or QQ group is the innovations of pharmacology teaching reform in combination with tend of the age, and they facilitate students to well master theoretical knowledge and develop students overall.

\section{References}

[1] R. Adhikari, J. Tocher, P. Smith, J. Corcoran, J. Macarthur. A multidisciplinary approach to medication safety and the implication for nursing education and practice. Nurse Educ Today, 2013, 24:pp.384-385

[2] Y.H. Lan, K.W. Wang, S. Yu, I.J. Chen, H.F. Wu, F.I. Tang. Medication errors in pediatric nursing: Assessment of nurses' knowledge and analysis of the consequences of errors. Nurse Educ Today, 2013, 27:pp.271-272.

[3] T. Dilles, R.R. Vander Stichele, L. Van Bortel, M.M. Elseviers. Nursing students' pharmacological knowledge and calculation skills: ready for practice? Nurse Educ Today, 2010, 31(5):pp.499-505.

[4] T. Papinczak, T. Tunny, L. Young. Conducting the symphony: a qualitative study of facilitation in problem-based learning tutorials. BMC Med Educ,2009, 43(4):pp. 377-383.

[5] Z. Yang, J. Xi. Bilingual medical education: opportunities and challenges. Med Educ,2009, 43(7):pp.613-614.

[6] K.D. Karpa, K.E. Vrana. Creating a Virtual Pharmacology Curriculum in a Problem-Based Learning Environment: One Medical School's Experience. Acad Med, 2013, 88(2):pp.198-205.

[7] O. Meade, D. Bowskill, J.S. Lymn. Pharmacology as a foreign language: a preliminary evaluation of audio as a supplementary learning tool for non-medical prescribing students. BMC Med Educ, 2009, 18(9):pp.74

[8] O. Meade, D. Bowskill, J.S. Lymn. Pharmacology podcasts: a qualitative study of non-medical prescribing students' use, perceptions and impact on learning. BMC Med Educ, 2011, 11:pp.2.

\section{Appendix The legends of Figure 1}

The flow-process of teaching and feedback information

After we teach pharmacology by "QQ group”, to "talk with" students, to do discuss under group, et al. Our teacher makes a questionnaire survey to know how and what students think about. Our flow-process is as follows (Fig. 1). Finally, we have analyzed the all of answers and draw a conclusion.

Almost all students think that it is the best platform, and usually visit the QQ groups. They suggested that all of homework and discuss could be finished through QQ groups, and it let easy to exchange massage between teacher and student, particularly be suitable for education in university. 